\title{
Níveis de energia metabolizável para machos de corte de crescimento lento criados em semiconfinamento
}

\author{
Michele de Oliveira Mendonça ${ }^{2,3}$, Nilva Kazue Sakomura ${ }^{3}$, Fabiana Ramos dos Santos ${ }^{3,4}$, \\ Ednardo Rodrigues Freitas ${ }^{3,5}$, João Batista Kochenborger Fernandes ${ }^{3}$, Nei André Arruda Barbosa ${ }^{3}$ \\ 1 Pesquisa financiada pela FAPESP. \\ ${ }^{2}$ Escola Agrotécnica Federal de Colorado do Oeste, Rodovia RO $399 \mathrm{~km} 5$ Caixa Postal 47, CEP: 78996-000, Colorado do Oeste, RO. \\ 3 UNESP/FCAV, Departamento de Zootecnia. Via de Acesso Professor Paulo Donato Castellane, s/n, CEP: 14884-900, Jaboticabal, SP. \\ ${ }^{4}$ Universidade Federal de Mato Grosso, Avenida Fernando Corrêa, s/n, Coxipó, Cuiabá-MT, CEP: 78060-900. \\ ${ }^{5}$ Universidade Federal do Ceará, Departamento de Zootecnia, Caixa Postal -12.168, CEP: 60355-970, Campus do Pici, Fortaleza, CE.
}

RESUMO - Foram conduzidos três ensaios para avaliar os níveis de energia metabolizável (EM) e a melhor relação energia:proteína (E:P) para aves de corte machos de crescimento lento criadas em semiconfinamento nas fases inicial ( 1 a 21), de crescimento (22 a 49) e de terminação (50 a 70 dias de idade). Em cada ensaio, 400 machos da linhagem ISA Label na fase de criação foram alojados em instalação experimental constituída de 20 piquetes com área coberta de 3,13 $\mathrm{m}^{2}$ para alimentação e recolhimento das aves e uma área de pastejo de $72,87 \mathrm{~m}^{2}$. O delineamento experimental foi o inteiramente casualizado com cinco tratamentos e quatro repetições de 20 aves. Os níveis de energia metabolizável fornecidos na ração na fase inicial variaram de 2.600 a $3.200 \mathrm{kcal} / \mathrm{kg}$; na fase de crescimento de 2.700 a $3.300 \mathrm{kcal} / \mathrm{kg}$; e na fase final de 2.800 a $3.400 \mathrm{kcal} / \mathrm{kg}$. A proteína bruta e os demais nutrientes foram mantidos constantes em todas as rações, de acordo com recomendações do NRC (1994) para cada fase. A relação energia:proteína e o nível de energia metabolizável que melhoraram o desempenho e as características da carcaça de frangos de corte ISA Label machos criados em sistema semiconfinado em cada fase estudada foram 128 e 2.750; 147 e 2.850 e 172 e $3.100 \mathrm{kcal}$ de EM/kg nas fases inicial, de crescimento e de terminação, respectivamente.

Palavras-chave: exigência de energia, linhagem ISA Label, relação energia:proteína

\section{Metabolizable energy levels for slow growth male broilers raised in semi confined system}

\begin{abstract}
Three trials were conducted to evaluate the metabolizable energy (ME) levels and the energy to protein ratio for slow growth male broilers raised in semi confined system in the starter (1 to 21), grower (22 to 49) and final phase (50 to 70 days old). In each experiment, 400 males ISA Label line in the raising phase were allotted to experimental installation constituted by 20 lots with cover area of $3.13 \mathrm{~m}^{2}$ for feeding and gathering of the birds and a pasture area of $72.87 \mathrm{~m}^{2}$. A completely randomized experimental design was used, with five levels of ME and four replications of 20 birds per experimental unit. The levels of metabolizable energy fed in the ration in the different phases varied in the starter from 2,600 to $3,200 \mathrm{kcal} / \mathrm{kg}$, in the grower from 2,700 to $3,300 \mathrm{kcal} / \mathrm{kg}$ and in the final from 2,800 to $3,400 \mathrm{kcal} / \mathrm{kg}$. The crude protein and other nutrients were maintained at the same level in all diets according to the NRC (1994) recommendations, for each phase. The energy to protein ratio and the metabolizable energy that provide the best performance and carcass traits of male broilers ISA Label raised in semi confined system in each phase were: 128 and 2,750, 147 and 2850 and 172 and 3,100 kcal ME/kg of diet in starter, grower and final phases, respectively.
\end{abstract}

Key Words: energy requirement, energy to protein ratio, ISA Label strain

\section{Introdução}

Os sistemas alternativos de produção avícola têm sido adotados por pequenos e médios produtores rurais com o objetivo de oferecer produtos diferenciados ao mercado consumidor, o que permite agregar maior valor em relação aos produzidos em sistema convencional.
A avicultura alternativa oferece produtos provenientes da criação de aves em sistema intensivo ou semi-intensivo, nos quais parte da alimentação é suprida por alimentos naturais, como forragens (pasto ou verde picado), insetos e minhocas e parte por rações balanceadas. Essas características atraíram uma parcela mais exigente da população, que se dispõe a pagar um pouco mais pelos produtos que 
proporcionem alimentação natural e saborosa (Albino et al., 2001). O sabor diferenciado da carne de aves criadas nesses sistemas se deve ao menor teor de gordura, à coloração mais avermelhada e à maior consistência da fibra em relação ao frango de corte de linhagem convencional (Silva et al., 2002).

A literatura tem mostrado que o desempenho das aves tem relação direta com o nível de energia da ração. Entretanto, poucas pesquisas para estudar exigências de energia para aves de crescimento lento criadas em semiconfinamento foram realizadas até o momento. Nesse contexto, o embasamento teórico é fundamentado nos trabalhos para estudar as exigências de energia metabolizável (EM) e a relação energia:proteína (E:P) para frangos de corte.

O NRC (1994) e Rostagno et al. (2000) recomendam para frangos de corte na fase inicial (1 a 21) as relações energia:proteína de 142 e 139, respectivamente, para a fase de crescimento (22 a 42) 160 e, para a fase final (43 a 56 dias), relação 178. A composição corporal pode ser influenciada por fatores genéticos, ambientais, fisiológicos e nutricionais. Diferenças nas deposições de gordura ou proteína não estão relacionadas à genética das aves, mas também à manipulação nutricional das dietas, principalmente quanto aos níveis de energia (Boekholt et al., 1994) e às relações energia:proteína (Macleod, 1990).

Considerando que aves de crescimento lento podem responder de forma diferente aos níveis energéticos e às relações energia:proteína, conduziu-se esta pesquisa com os objetivos de determinar níveis de energia metabolizável e a melhor relação energia:proteína para machos de uma linhagem de corte de crescimento lento criados em semiconfinamento nas fases inicial (1 a 21), de crescimento (22 a 49) e de terminação (50 a 70 dias de idade).

\section{Material e Métodos}

Três ensaios foram realizados no Setor de Avicultura do Departamento de Zootecnia da Faculdade de Ciências Agrárias e Veterinárias - FCAV/UNESP, Jaboticabal, São Paulo, para determinar as exigências de energia metabolizável e a melhor relação energia:proteína nas fases inicial, de crescimento e final.

Para a formação das unidades experimentais, foi criado um lote de machos da linhagem ISA Label em um galpão convencional com densidade de 10 aves $/ \mathrm{m}^{2}$. À medida que os ensaios eram conduzidos, as aves eram selecionadas com base no peso individual e distribuídas entre os tratamentos de modo que as parcelas apresentassem pesos médios semelhantes. As aves mantidas no galpão foram alimentadas com ração única contendo 2.900, 3.000 e $3.100 \mathrm{kcal}$ de EM/kg para as fases inicial (1 a 21), de crescimento (22 a 49) e de terminação (50 a 70 dias de idade), respectivamente.

Em cada fase, 400 aves foram alojadas nas instalações experimentais, dotadas de um sistema de semiconfinamento constituído de 20 piquetes, cada um com área coberta de $3,13 \mathrm{~m}^{2}$ com cama de maravalha, comedouros e bebedouros pendulares e uma área de pastejo com 72,87 $\mathrm{m}^{2}$. Em cada piquete, foram alojadas 20 aves, totalizando uma área de pastejo de no mínimo $3 \mathrm{~m}^{2}$ por ave. Pela manhã, as aves eram soltas e recolhidas para a área coberta no final da tarde. Os frangos foram mantidos na área coberta até os 21 dias de idade (início da fase de crescimento), quando tiveram acesso somente ao pasto.

O delineamento experimental adotado em todas as fases foi o inteiramente casualizado com cinco tratamentos e quatro repetições de 20 aves por repetição. Na fase inicial, foram estudados os seguintes níveis de energia metabolizável (EM): 2.600, 2.750, 2.900, 3.050 e $3.200 \mathrm{kcal} / \mathrm{kg}$ da ração. O nível de proteína bruta (PB) foi mantido em 21,40\% para fornecimento das seguintes relações energia:proteína: $121,128,135,142$ e 149.

Os níveis de 2.700, 2.850, 3.000, 3.150 e 3.300 kcal de $\mathrm{EM} / \mathrm{kg}$ da ração foram avaliados na fase de crescimento utilizando-se rações com 19,35\% de PB. Dessa forma, as relações energia:proteína foram: 139, 147, 155, 162 e 170.

No período de 50 a 70 dias de idade, foram analisados os níveis de 2.800, 2.950, 3.100, 3.250 e 3.400 kcal de EM/kg da ração com o nível de PB de 18\%, o que resultou nas seguintes relações energia:proteína: 156, 164, 172, 181 e 189. Em cada fase, os níveis dos demais nutrientes foram mantidos constantes em todos os tratamentos, de acordo com as recomendações do NRC (1994).

As rações foram formuladas à base de milho e farelo de soja e foram adicionadas de óleo vegetal para ajuste dos níveis de energia metabolizável (Tabela 1). Os valores de composição dos alimentos utilizados nas rações estão de acordo com os descritos por Rostagno et al. (2000).

Os valores de energia metabolizável aparente corrigida pelo balanço de nitrogênio (EMAn) das rações utilizadas nas respectivas fases foram determinados em ensaios de digestibilidade realizados anteriormente. Os níveis de energia metabolizável das rações experimentais foram obtidos pela mistura da ração com nível mais baixo de energia metabolizável (2.600, 2.700 e $2.800 \mathrm{kcal} / \mathrm{kg}$ ) com a ração com nível mais alto de energia (3.200, 3.300 e $3.400 \mathrm{kcal} / \mathrm{kg}$ ), respectivamente nas fases inicial, crescimento e final (Tabela 2). 
Tabela 1 - Composição das rações experimentais utilizadas nas fases de criação

\begin{tabular}{|c|c|c|c|c|c|c|}
\hline \multirow[t]{2}{*}{ Ingrediente } & \multicolumn{6}{|c|}{ Tratamento } \\
\hline & 2.600 & 3.200 & 2.700 & 3.300 & 2.800 & 3.400 \\
\hline Milho & 51,840 & 53,223 & 58,851 & 58,705 & 64,650 & 61,667 \\
\hline Farelo de soja & 37,227 & 36,969 & 31,416 & 31,444 & 27,317 & 27,877 \\
\hline Óleo & 0,000 & 6,363 & 0,000 & 6,875 & 0,000 & 7,825 \\
\hline Calcário & 1,023 & 1,026 & 1,144 & 1,143 & 1,120 & 1,113 \\
\hline Sal comum & 0,375 & 0,375 & 0,279 & 0,280 & 0,207 & 0,208 \\
\hline DL-metionina 99\% & 0,177 & 0,175 & 0,084 & 0,084 & 0,033 & 0,034 \\
\hline Coxistac $^{2}$ & 0,055 & 0,055 & 0,055 & 0,055 & 0,055 & 0,055 \\
\hline Surmax $^{3}$ & 0,003 & 0,003 & 0,003 & 0,003 & 0,003 & 0,003 \\
\hline Mistura vitamínica ${ }^{4}$ & 0,100 & 0,100 & 0,100 & 0,100 & 0,100 & 0,100 \\
\hline Mistura mineral $^{5}$ & 0,050 & 0,050 & 0,050 & 0,050 & 0,050 & 0,050 \\
\hline
\end{tabular}

${ }^{1}$ Areia lavada.

${ }^{2}$ Anticoccidiano - Salinomicina $12 \%$.

3 Promotor de crescimento - avilamicina.

${ }^{4}$ Mistura vitamínica (quantidade/kg do produto): vit. A - 8.000.000 Ul; vit. $\mathrm{B}_{12}-10.000 \mathrm{mcg}$; vit. $\mathrm{D}_{3}-2.000 .000 \mathrm{Ul}$; vit. E - $15.000 \mathrm{mg}$; vit. $\mathrm{K}_{3}-2000 \mathrm{mg}$ ácido fólico - $700 \mathrm{mg}$; ácido pantotênico - $8000 \mathrm{mg}$; biotina - $60 \mathrm{mg}$; niacina - $30.000 \mathrm{mg}$; Se - $400 \mathrm{mg}$; antioxidante - $5000 \mathrm{mg}$; riboflavina - $4000 \mathrm{mg}$; tiamina - $1.000 \mathrm{mg}$, piridoxina - $2.000 \mathrm{mg}$.

${ }^{5}$ Mistura mineral - (quantidade/kg do produto): Mn - $126.000 \mathrm{mg} ; \mathrm{Zn}-126.000 \mathrm{mg}$; Fe - $105.000 \mathrm{mg} ; \mathrm{Cu}-12.600 \mathrm{mg} ; \mathrm{I}-2520 \mathrm{mg}$.

Tabela 2 - Composição calculada e proporções das rações experimentais utilizadas nas fases de criação

\begin{tabular}{|c|c|c|c|c|c|c|}
\hline Nutriente & \multicolumn{6}{|c|}{ Nível de energia metabolizável (kcal/kg) } \\
\hline Proteína bruta (\%) & 21,4 & 21,4 & 19,35 & 19,35 & 18,00 & 18,00 \\
\hline Metionina (\%) & 0,505 & 0,504 & 0,387 & 0,387 & 0,320 & 0,320 \\
\hline Metionina + cistina (\%) & 0,840 & 0,840 & 0,700 & 0,700 & 0,619 & 0,616 \\
\hline Treonina (\%) & 0,834 & 0,834 & 0,753 & 0,753 & 0,700 & 0,700 \\
\hline Fósforo disponível (\%) & 0,420 & 0,420 & 0,340 & 0,340 & 0,300 & 0,300 \\
\hline Sódio (\%) & 0,190 & 0,190 & 0,150 & 0,150 & 0,120 & 0,120 \\
\hline Ração & 2.600 & 2.750 & & & 3.050 & 3.200 \\
\hline Tratamento 1 & $100 \%$ & $75 \%$ & & & $25 \%$ & 0 \\
\hline Tratamento 5 & 0 & $25 \%$ & & & $75 \%$ & $100 \%$ \\
\hline
\end{tabular}

Em todos os ensaios, foram avaliados os consumos de ração (g/ave), proteína (g/ave) e energia metabolizável (Mcal/ave), o ganho de peso (g/ave) e as conversões alimentar (g ração/g de ganho de peso) e calórica (Mcal consumida/ g de ganho de peso). O consumo de energia metabolizável e a conversão calórica foram obtidos a partir dos valores de EMAn determinados das rações utilizadas nas respectivas fases.

Ao final dos ensaios de crescimento (49 dias) e terminação (70 dias), três aves de cada parcela experimental com peso próximo ao peso médio obtido para a parcela foram selecionadas e, após jejum de 12 horas, foram abatidas para avaliação das características de carcaça (rendimento de carcaça, peito, coxa e sobrecoxa) e da porcentagem de gordura abdominal. O rendimento de carcaça foi obtido em relação ao peso vivo das aves em jejum e o rendimento dos demais cortes foi calculado em relação ao peso da carcaça eviscerada. Foi considerado gordura abdominal o tecido adiposo aderido em torno da cloaca, da moela e dos músculos abdominais adjacentes.

Foram realizados abates no início e ao final de cada ensaio para determinar as deposições de proteína e gordura corporal. $\mathrm{O}$ abate inicial foi realizado em um grupo de 12 aves (quatro repetições de três aves) com peso próximo ao peso médio no início de cada ensaio e, no abate final, foram escolhidas três aves de cada parcela com peso próximo ao peso médio da parcela.

Após o abate, as carcaças foram congeladas e autoclavadas para obtenção de uma amostra representativa. As aves foram acondicionadas em recipientes de inox espe- 
cíficos para autoclave (AV-225, PHOENIX, São Paulo) e mantidas a $127^{\circ} \mathrm{C}$ e $1 \mathrm{~atm}$. Os pintos de 1 dia e 22 dias de idade foram submetidos a esta temperatura e pressão por 3 horas e as aves mais velhas por 5 horas. Após este procedimento, as amostras foram homogeneizadas em liquidificador industrial (8 L Skynsem, São Paulo), secas em estufa $55^{\circ} \mathrm{C}$ por 72 horas (amostra seca ao ar), trituradas em moinho de bola (MA-350, Marconi, São Paulo) e acondicionadas em recipientes identificados e congeladas. Posteriormente, foram encaminhadas ao laboratório para determinação dos teores de matéria seca, extrato etéreo e proteína bruta, de acordo com a metodologia descrita por Silva \& Queiroz (2002).

Os dados obtidos foram analisados pelo procedimento GLM do programa computacional SAS (1999). As estimativas das exigências foram determinadas pelo modelo de regressão polinomial.

\section{Resultados e Discussão}

Assim como as linhagens comerciais de frangos de corte que regulam o consumo (Leeson et al., 1996), o aumento dos níveis de energia metabolizável reduziram linearmente $(\mathrm{P}<0,05)$ o consumo de ração $(\mathrm{CR})$ em todos os períodos estudados (Tabelas 3, 4 e 5). Outros autores (Nobre et al., 1994; Avila et al., 2004) também verificaram redução no consumo de ração quando elevaram o conteúdo energético das rações. Esse resultado comprova que o nível de energia metabolizável (EM) controla o consumo de alimento, o que confirma a necessidade de adequação de todos os nutrientes da dieta ao seu conteúdo energético.

Embora o consumo de ração tenha sido regulado pelos níveis de energia, o aumento da ingestão de EM (IEM) ocorreu de forma linear ao aumento dos níveis de energia metabolizável da ração, uma vez que o mecanismo de regulação da ingestão de alimento em relação à energia da ração não é fisiologicamente perfeito e as aves alimentadas com rações mais energéticas acabam ingerindo maior quantidade de energia, como observado por Nobre et al. (1994), Leeson et al. (1996), Oliveira Neto et al. (1999) e Oliveira Neto et al. (2000).

A ingestão de proteína (IPB) reduziu de forma linear com o aumento da energia metabolizável da ração, apesar de as rações experimentais apresentarem o mesmo teor de proteína bruta. Esse resultado está relacionado ao fato de as aves terem diminuído o consumo de ração à medida que a densidade energética das rações foi aumentada. Esse resultado confirma o obtido por Silva et al. (2001), que observaram forte correlação negativa $(r=-0,935 ; \mathrm{P}<0,0001)$ entre o consumo de proteína e a relação energia:proteína de dietas para frangos de corte no período de 22 a 42 dias de idade.

Não houve efeito dos níveis de energia da ração sobre o ganho de peso (GP) de machos ISA Label nos períodos de 1 a 21 e 22 a 49 dias de idade. Apesar de o ganho de peso depender da ingestão de nutrientes, as alterações na ingestão de energia e proteína com o aumento da energia metabolizável das rações não promoveram diferenças significativas nesta variável, principalmente quando as relações energia:proteína variaram de 121 a 149 e 147 a 170 nas fases inicial e crescimento, respectivamente.

Leeson et al. (1996) também não verificaram efeito dos níveis de energia sobre o ganho de peso (GP) de frangos de corte na fase inicial. A ampliação da relação energia:proteína durante a fase de crescimento não afetou

Tabela 3 - Características de desempenho de aves de corte machos de crescimento lento no período de 1 a 21 dias de idade

\begin{tabular}{|c|c|c|c|c|c|c|c|}
\hline \multirow[t]{4}{*}{ Variável } & \multicolumn{5}{|c|}{ Nível de energia metabolizável (kcal/kg) } & \multirow[t]{4}{*}{ CV (\%) } & \multirow[t]{4}{*}{ Probabilidade } \\
\hline & 2.600 & 2.750 & 2.900 & 3.050 & 3.200 & & \\
\hline & \multicolumn{5}{|c|}{ Relação energia:proteína } & & \\
\hline & 121 & 128 & 135 & 142 & 149 & & \\
\hline Consumo de ração (g/ave) & $688 a$ & $670 \mathrm{ab}$ & $644 b$ & $610 c$ & $588 c$ & 2,97 & $<0,0001$ \\
\hline Ganho de peso (g/ave) & $382 \mathrm{a}$ & $388 a$ & $381 a$ & $391 \mathrm{a}$ & $386 a$ & 4,22 & 0,9156 \\
\hline Conversão alimentar & $1,80 \mathrm{a}$ & $1,73 \mathrm{a}$ & $1,70 \mathrm{a}$ & $1,56 b$ & $1,53 b$ & 4,53 & 0,0005 \\
\hline Conversão calórica ${ }^{1}$ & 4,55 аа & $4,62 \mathrm{a}$ & $4,84 a$ & $4,63 a$ & $4,86 a$ & 4,53 & 0,1775 \\
\hline Ingestão de EM (Mcal/ave) ${ }^{1}$ & $1,74 \mathrm{~b}$ & $1,79 \mathrm{ab}$ & $1,84 \mathrm{ab}$ & $1,81 \mathrm{ab}$ & $1,88 a$ & 2,96 & 0,0248 \\
\hline Ingestão de PB (g/ave) & 148 a & $144 \mathrm{ab}$ & $138 b$ & 131c & $126 \mathrm{c}$ & 2,97 & $<0,0001$ \\
\hline Deposição gordura corporal (g/ave) & $24,58 a$ & $23,52 \mathrm{a}$ & $27,35 \mathrm{a}$ & $28,78 \mathrm{a}$ & $29,52 \mathrm{a}$ & 17,71 & 0,3753 \\
\hline Deposição de proteína corporal (g/ave) & $73,63 \mathrm{a}$ & $72,98 \mathrm{a}$ & $71,95 \mathrm{a}$ & $76,15 \mathrm{a}$ & $75,48 \mathrm{a}$ & 3,35 & 0,2233 \\
\hline
\end{tabular}

${ }^{1}$ Ingestão de proteína bruta $=245,767-37,3025 E M ; R^{2}=0,83(P<0,0001)$.

Consumo de ração $=1,1431-0,1735 E M ; R^{2}=0,83(P<0,0001)$

Conversão alimentar $=3,0395-0,4750 E M ; R^{2}=0,68(P<0,0001)$. Ingestão de energia metabolizável $=1,2295+0,2000$ EM; $R^{2}=0,41(P=0,0023)$.

Variáveis calculadas considerando os valores de EMAn determinados em ensaio de digestibilidade.

Valor de EMAn determinado (valor de EMAn calculado): 2.525 (2.600), 2.673 (2.750), 2.852 (2.900), 2.964 (3.050) e 3.191 (3.200) kcal/kg de matéria natural Médias seguidas por letras diferentes diferem $(P<0,05)$ entre si pelo teste SNK. 
Tabela 4 - Características de desempenho de aves de corte machos de crescimento lento no período de 22 a 49 dias de idade

\begin{tabular}{|c|c|c|c|c|c|c|c|}
\hline \multirow[t]{2}{*}{ Variável } & \multicolumn{5}{|c|}{ Nível de energia metabolizável (kcal/kg) } & \multirow[t]{2}{*}{ CV (\%) } & \multirow[t]{2}{*}{ Probabilidade } \\
\hline & 2.700 & 2.850 & 3.000 & 3.150 & 3.300 & & \\
\hline & \multicolumn{5}{|c|}{ Relação energia:proteína } & & \\
\hline & 139 & 147 & 155 & 162 & 170 & & \\
\hline Consumo de ração (g/ave) & $2.361 \mathrm{a}$ & $2.256 \mathrm{ab}$ & $2.260 \mathrm{ab}$ & $2.169 b$ & $2.112 b$ & 3,35 & 0,0030 \\
\hline Ganho de peso (g/ave) & 963a & $992 \mathrm{a}$ & 998a & $1.014 \mathrm{a}$ & $1.009 \mathrm{a}$ & 3,55 & 0,3008 \\
\hline Conversão alimentar & $2,45 a$ & $2,28 b$ & $2,27 b$ & $2,14 c$ & $2,10 \mathrm{c}$ & 2,25 & $<0,0001$ \\
\hline 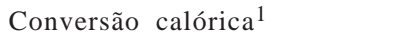 & $6,53 \mathrm{bc}$ & $6,38 c$ & $6,75 b$ & $6,83 a$ & $6,98 a$ & 2,44 & 0,0008 \\
\hline Ingestão EM (Mcal/ave) ${ }^{2}$ & $6,28 b$ & $6,32 b$ & $6,74 a$ & 6,93a & $7,04 \mathrm{a}$ & 3,28 & 0,0004 \\
\hline Ingestão PB (g/ave) & $458 \mathrm{a}$ & $438 a b$ & $438 a b$ & $421 b$ & $410 \mathrm{~b}$ & 3,35 & 0,0031 \\
\hline Deposição de gordura (g/ave) & $79,85 a$ & $89,98 a$ & $96,90 \mathrm{a}$ & $97,87 \mathrm{a}$ & $100,09 a$ & 12,96 & 0,1942 \\
\hline Deposição de proteína (g/ave) & $192,67 a$ & $193,60 a$ & $203,68 a$ & $202,39 a$ & 194,93a & 7,35 & 0,8287 \\
\hline Rendimento carcaça (\%) & $71,71 \mathrm{a}$ & $70,35 a$ & $71,42 \mathrm{a}$ & $70,74 a$ & $73,00 \mathrm{a}$ & 3,40 & 0,5987 \\
\hline Rendimento peito (\%) & $27,90 \mathrm{a}$ & $26,91 \mathrm{a}$ & $27,32 \mathrm{a}$ & $26,34 \mathrm{a}$ & $26,63 a$ & 2,74 & 0,0673 \\
\hline Rendimento pernas (\%) & $32,51 \mathrm{a}$ & $33,09 a$ & 33,03a & $33,61 \mathrm{a}$ & $34,07 \mathrm{a}$ & 2,14 & 0,0630 \\
\hline Gordura abdominal (\%) & 1,20b & $1,56 \mathrm{ab}$ & $1,67 \mathrm{ab}$ & 2,30a & 2,41a & 25,86 & 0,0060 \\
\hline
\end{tabular}

Médias seguidas por letras diferentes diferem $(P<0,05)$ entre si pelo teste SNK.

Consumo de ração $=3,4006-0,3897 \mathrm{EM} ; R^{2}=0,60(P<0,0001)$.

Conversão alimentar $=3,9555-0,5700 \mathrm{EM}, \mathrm{R}^{2}=0,83(\mathrm{P}<0,0001)$.

Conversão calórica $=3,9725+0,9067 \mathrm{EM} ; R^{2}=0,56(P=0,0002)$.

Ingestão de $E M=2,4105+1,4167 E M ; R^{2}=0,68(P<0,0001)$.

Ingestão de PB = 659,628 - 75,5653EM; $R^{2}=0,60(P<0,0001)$

Porcentagem de gordura abdominal $=-6,3225+2,7850 E M ; R^{2}=0,45(P=0,0012)$.

${ }^{1}$ Variáveis calculadas considerando os valores de EMAn determinados em ensaio de digestibilidade.

${ }^{2}$ Valor de EMAn determinado (valor de EMAn calculado): 2.661 (2.700), 2.801 (2.850), 2.981 (3.000), 3.194 (3.150) e 3.332 (3.300) kcal/kg de matéria natural.

Tabela 5 - Características de desempenho de aves de corte machos de crescimento lento no período de 50 a 70 dias de idade

\begin{tabular}{|c|c|c|c|c|c|c|c|}
\hline Variável & \multicolumn{5}{|c|}{ Nível de energia metabolizável (kcal/kg) } & CV (\%) & Probabilidade \\
\hline & \multicolumn{5}{|c|}{ Relação energia:proteína } & & \\
\hline & 156 & 164 & 172 & 181 & 189 & & \\
\hline Consumo de ração (g/ave) & $2677 a$ & $2659 a$ & $2632 a$ & 2534b & $2443 c$ & 2,03 & $<0,0001$ \\
\hline Ganho de peso (g/ave) & $818 c$ & 866b & $928 \mathrm{a}$ & $934 a$ & $906 a$ & 2,43 & $<0,0001$ \\
\hline Ingestão EM (Mcal/ave) ${ }^{2}$ & $7,99 \mathrm{~d}$ & $8,32 c$ & $8,63 b$ & $8,53 \mathrm{bc}$ & $8,96 a$ & 1,97 & $<0,0001$ \\
\hline Ingestão PB (g/ave) & $482 \mathrm{a}$ & $479 a$ & $474 a$ & 456b & $440 c$ & 2,03 & $<0,0001$ \\
\hline Deposição de gordura (g/ave) & $99,49 a$ & $105,36 a$ & $139,92 \mathrm{a}$ & $141,83 a$ & $142,02 \mathrm{a}$ & 21,75 & 0,2165 \\
\hline Deposição de proteína (g/ave) & $171,94 a$ & $172,86 a$ & $188,45 a$ & $179,66 a$ & $175,74 a$ & 5,74 & 0,3117 \\
\hline Rendimento carcaça (\%) & $71,07 \mathrm{a}$ & $72,09 \mathrm{a}$ & 71,83a & $71,51 \mathrm{a}$ & $70,73 a$ & 1,30 & 0,2765 \\
\hline Rendimento peito (\%) & $28,31 \mathrm{a}$ & $27,78 \mathrm{a}$ & $27,67 a$ & $27,62 \mathrm{a}$ & $28,14 a$ & 2,35 & 0,5076 \\
\hline
\end{tabular}

Médias seguidas por letras diferentes diferem $(\mathrm{P}<0,05)$ entre si pelo teste SNK.

Consumo de ração $=3,8149-0,3955 \mathrm{EM}, \mathrm{R}^{2}=0,72(\mathrm{P}<0,0001)$.

Ganho de peso $=-5,9349+4,2607 \mathrm{EM}-0,6611 \mathrm{EM}^{2}, \mathrm{R}^{2}=0,81(P<0,0001)$

Conversão alimentar $=20,8271-10,5969 \mathrm{EM}-1,5476 \mathrm{EM}^{2}, \mathrm{R}^{2}=0,94(P<0,0001)$

Conversão calórica $=69,8965-38,9721 \mathrm{EM}+6,2619 \mathrm{EM}^{2}, \mathrm{R}^{2}=0,51(\mathrm{P}=0,0023)$.

Ingestão de $E M=4,0680+1,4250 E M, R^{2}=0,74(P<0,0001)$.

Ingestão de PB $=686,6900-71,1900 E M, R^{2}=0,72(P<0,0001)$

Deposição de gordura $=89,7744+13,1753 \mathrm{EM}, R^{2}=0,37(P=0,0167)$.

Porcentagem de gordura abdominal $=-70,2847+45,7982 \mathrm{EM}-7,1349 \mathrm{EM}^{2}, \mathrm{R}^{2}=0,48(P=0,0036)$.

${ }^{1}$ Variáveis calculadas considerando os valores de EMAn determinados em ensaio de digestibilidade.

${ }^{2}$ Valor de EMAn determinado (valor de EMAn calculado): 2.984 (2.800), 3.130 (2.950), 3.279 (3.100), 3.366 (3.250) e 3.667 (3.400) kcal/kg de matéria natural.

significativamente o ganho de peso de frangos Ross alimentados com dieta de alta ou baixa energia (Reginatto et al., 2000).

O ganho de peso dos frangos ISA Label machos atingiu um platô com $3.222 \mathrm{kcal}$ de EM/kg (Tabela 5). Como esta variável depende da ingestão de nutrientes (Freitas et al., 2006), a redução significativa do ganho de peso a partir do nível de $3.250 \mathrm{kcal} / \mathrm{kg}$ reduziu o ganho de peso das aves. Deaton \& Lott (1985) sugeriram um limite da resposta no crescimento das aves ao aumento da densidade energética 
das dietas. De acordo com esses autores, o limite superior para se obter resposta com frangos de corte foi o nível de $3.250 \mathrm{kcal}$ de $\mathrm{EM} / \mathrm{kg}$.

Segundo Noy \& Sklan (2002), algumas pesquisas comprovaram que o aumento nos níveis energéticos das dietas promove aumento no ganho de peso de frangos de corte, enquanto outras indicam que esta variável atinge um platô e depois de determinado nível as aves não respondem mais ao aumento de energia das rações. Como o ganho de peso não foi alterado e houve redução no consumo de ração, à medida que aumentou a densidade energética das dietas, a conversão alimentar (CA) melhorou nos períodos de 1 a 21 e 22 a 49 dias de idade. Esse resultado corrobora os obtidos por Leeson et al. (1996), Oliveira Neto et al. (2000) e Silva et al. (2001) em frangos de corte. O aumento do nível de energia por meio de inclusão de óleo de soja nas rações pode proporcionar menor incremento calórico e, conseqüentemente, aumentar a energia disponível para a ave, além de modificar a taxa de passagem e a digestibilidade do alimento, fatores que justificam, em parte, a melhora na conversão alimentar de frangos de corte (Oliveira Neto et al., 1999).

A conversão alimentar apresentou comportamento quadrático na fase final (Tabela 5). Waldroup (1996) verificou que o ganho de peso de frangos na fase de crescimento atingiu um platô e não respondeu ao aumento da energia da ração. Segundo esse autor, esse fato pode explicar a tendência de a conversão alimentar melhorar até certo nível e depois piorar com o aumento do conteúdo energético da dieta. Entretanto, outras pesquisas (Silva et al., 2001; Ávila et al., 2004) comprovaram melhoria linear na conversão alimentar de frangos de corte alimentados com rações com diferentes níveis de energia metabolizável.

Apesar de terem aumentado a ingestão de energia metabolizável, os frangos de crescimento lento não apresentaram diferença significativa na conversão calórica (CC) aos 21 dias de idade. Stringhini et al. (2000) também não notaram efeito dos níveis de energia e proteína sobre esta variável em frangos de corte machos na fase inicial.

No entanto, na fase de crescimento, o nível de energia não influenciou o ganho de peso e a ingestão de energia metabolizável aumentou linearmente promovendo piora na conversão calórica, demonstrando que, ao aumentar apenas os níveis energéticos das rações, as aves podem ter perdido a eficiência em converter a energia para ganhar peso. Noy \& Sklan (2002) verificaram que o aumento da energia da ração com a inclusão de óleo diminui a eficiência de utilização da energia para o ganho de peso resultando em pior conversão calórica.

Como os níveis de energia tiveram efeito significativo sobre o ganho de peso e a ingestão de energia metabolizável no período de 50 a 70 dias de idade, a conversão calórica apresentou comportamento quadrático (Tabela 5) (CC = 69,8965-38,9721*EM +6,2619EM ${ }^{2}$ ). As aves alimentadas com rações contendo $3.400 \mathrm{kcal}$ de EM/kg aumentaram a ingestão de energia metabolizável, mas não ganharam mais peso, em virtude da redução no consumo de ração, desta forma, a conversão calórica piorou. Esse resultado corrobora o obtido por Waldroup et al. (1976), que observaram que o nível de $3.112 \mathrm{kcal}$ de EM/kg foi suficiente para melhorar esta variável em frangos de corte ISA Label machos nesse período.

Os níveis de energia metabolizável estudados nas três fases não influenciaram a deposição de proteína corporal das aves. A deposição protéica é controlada pela genética da ave. Independentemente da ingestão, ocorre limite diário de deposição, o que não pode ser compensado (Albino et al., 2000). Bertechini et al. (1991) também não observaram diferenças nos teores de proteína na carcaça de frangos de corte alimentados com dietas de diferentes conteúdos energéticos.

Apesar de a deposição de gordura na carcaça não ter sido afetada pelos níveis energéticos da ração nos períodos de 1 a 21 e de 22 a 49 dias de idade, as aves mostraram tendência em depositar mais gordura quando fornecidos níveis mais altos de energia.

Esse efeito pode ser atribuído principalmente à maior ingestão de energia metabolizável com o aumento da energia metabolizável dietética, o que promoveu excedente de energia além da mantença e deposição de tecido magro, que foi depositado como gordura. $O$ alto coeficiente de variação de deposição de gordura (17,71 e 12,96\%, respectivamente nas fases de 1 a 21 e de 22 a 49 dias) foi o segundo fator que contribuiu para não terem sido detectadas diferenças significativas nesta variável. Griffiths et al. (1977) afirmaram que essa variação individual na quantidade de gordura entre animais de mesma espécie é expressa como aumento do coeficiente de variação que suprime as diferenças entre níveis de energia metabolizável da dieta.

As aves criadas em semiconfinamento neste experimento aumentaram linearmente a deposição de gordura na carcaça à medida que o nível de energia da ração aumentou na última fase. Com a mais alta relação energia:proteína, as aves aumentaram a ingestão de energia metabolizável (Tabela 5), o que levou a maior deposição de gordura. Como observado por Boekholt et al. (1994), quando há aumento no consumo de energia metabolizável da dieta, a retenção de energia na forma de gordura aumenta linearmente. Kessler et al. (2000) explicaram que a quantidade de gordura depositada é diretamente proporcional à quantidade de energia disponível para síntese, portanto, a 
energia alimentar em excesso é bem correlacionada à deposição de lipídios na maioria dos animais.

O rendimento de carcaça e dos cortes nobres (coxa + sobrecoxa e peito) dos machos não foi influenciado pelos níveis de energia estudados (Tabelas 4 e 5). Oliveira Neto et al. (1999) também verificaram que os níveis energéticos da ração não alteraram os rendimentos de carcaça, de pernas e de peito.

No entanto, a porcentagem de gordura abdominal aumentou à medida que os níveis de energia metabolizável da ração aumentaram. De acordo com Trindade et al. (1982), quanto maior a relação energia:proteína, maior a quantidade de gordura abdominal depositada. Como os custos energéticos de deposição de proteína e síntese de ácido úrico reduzem de acordo com o aumento dessa relação energia:proteína, mais energia fica disponível para a deposição de gordura na carcaça (Silva et al., 2001).

O controle da ingestão de energia é importante não somente por seu efeito na taxa de crescimento, mas também pelos efeitos negativos da ingestão em excesso, que deprecia a qualidade da carcaça pelo maior acúmulo de gordura. Reduções nos níveis de energia da dieta resultam em menor acúmulo de gordura na carcaça (Leeson et al., 1996).

A gordura abdominal não é influenciada pelo nível de energia da ração quando se mantém fixa a relação energia:proteína (Waldroup, 1996). Como neste ensaio houve variação nesta relação, os níveis energéticos tiveram efeito significativo sobre a porcentagem de gordura abdominal das aves. Pesquisadores têm relatado que, com o aumento da proteína bruta da dieta ou a redução na relação energia:proteína, ocorrem diminuição no conteúdo de gordura da carcaça e aumento na proporção de água e proteína (Morris et al., 1999).

Os resultados obtidos evidenciaram que o aumento no nível de energia metabolizável da ração tendeu a aumentar a deposição de gordura e a porcentagem de gordura abdominal e piorar a conversão calórica, porém melhorou a conversão alimentar e não influenciou o ganho de peso das aves na fase inicial. Apesar da melhora linear na conversão alimentar, o nível de $2.750 \mathrm{kcal}$ de EM/kg, correspondente à relação energia:proteína de 128 , proporcionou os melhores resultados de conversão calórica e deposição de gordura na carcaça de frangos de corte ISA Label machos na fase de 1 a 21 dias de idade.

As aves demonstraram exigir menor teor de energia metabolizável e mais baixa relação energia:proteína na ração em comparação a frangos de corte. Zanusso et al. (1999), apesar de terem observado melhora linear no ganho de peso e na conversão alimentar, concluíram que o nível de
$3.075 \mathrm{kcal}$ de EM/kg (relação energia:proteína de 139) proporcionou os melhores resultados de desempenho em frangos machos na fase de 1 a 21 dias de idade. A relação energia:proteína recomendada por esses autores está de acordo com a sugerida por Reginatto et al. (2000) e Rostagno et al. (2000) para a mesma fase estudada.

A ração de maior nível energético (3.300 kcal de EM/kg) proporcionou melhor conversão alimentar, pior conversão calórica e maior quantidade de gordura tanto na região abdominal como na carcaça, mas não promoveu maior ganho de peso e deposição de proteína na carcaça. Ainda que a conversão alimentar tenha melhorado linearmente com o aumento dos níveis de energia da dieta, o nível de $2.850 \mathrm{kcal}$ de EM/kg e a relação energia:proteína de 147 proporcionou melhores resultados de desempenho e menor quantidade de gordura na carcaça de aves criadas em semiconfinamento no período de 22 a 49 dias de idade.

A relação energia:proteína recomendada para machos da linhagem ISA Label na fase de crescimento é semelhante à sugerida por Silva et al. (2001), que verificaram que a relação de 148 (3100 kcal/ 20,95\% PB) foi suficiente para permitir ótimo crescimento de frangos de corte no período de 22 a 42 dias de idade. Embora o nível de energia de $3.100 \mathrm{kcal}$ de EM/kg seja o mesmo sugerido por Rostagno et al. (2000) para esta fase, a relação energia:proteína sugerida por Silva et al. (2001) e para aves de corte de crescimento lento é inferior à recomendada por esses autores e pelo NRC (1994), de 160.

No período de 50 a 70 dias de idade, considerando a conversão calórica e as demais características de desempenho e qualidade da carcaça, o nível de $3.100 \mathrm{kcal}$ de EM/kg, correspondente à relação energia:proteína de 172, promoveu os melhores resultados em frangos de corte machos da linhagem ISA Label.

\section{Conclusões}

A relação energia:proteína e o nível de energia metabolizável que promovem maior desempenho e melhores características de carcaça de aves de corte machos de crescimento lento criados em semiconfinamento são $128 \mathrm{e}$ 2.750 (fase inicial), 147 e 2.850 (fase de crescimento) e 172 e 3.100 kcal de EM/kg de ração (fase de terminação).

\section{Literatura Citada}

ALBINO, L.F.T.; NASCIMENTO, A.H.; VALERIO, S.R. Níveis de energia da dieta e da temperatura ambiente sobre a composição da carcaça em frangos (músculo e gordura). In: SIMPOSIO INTERNACIONAL SOBRE DESENVOLVIMENTO DE CARCAÇA DE FRANGOS: 
OSSO, MÚSCULO, GORDURA E PENA, CONFERÊNCIA APINCO DE CIÊNCIA E TECNOLOGIA AVÍCOLAS, 2000, Campinas. Anais... Campinas: APINCO, 2000. p.63-79.

ALBINO, L.F.T; VARGAS JR., J.G.; SILVA, J.H.V. Criação de frango e galinha caipira - avicultura alternativa. Viçosa: Aprenda Fácil, 2001. 110p.

AVILA, V.S.; BRUM, P.A.R.; COLDEBELlA, A. et al. Níveis de energia metabolizável para frangos de corte tipo caipira ou colonial, "ISA Label”, em dois sistemas de criação. In: REUNIÃO ANUAL DA SOCIEDADE BRASILEIRA DE ZOOTECNIA, 41., 2004, Campo Grande. Anais... Campo Grande: Sociedade Brasileira de Zootecnia, 2004. (CD-ROM).

BERTECHINI, A.G.; ROSTAGNO, H.S.; FONSECA, J.B. et al. Efeito da forma física e nível de energia da ração sobre desempenho e carcaça de frangos de corte. Revista da Sociedade Brasileira de Zootecnia, v.20, n.3, p.229-240, 1991.

BOEKHOLT, H.A.; Van der GRINTEN, P.H.; SCHREUS, A. et al. Effect of dietary energy restriction on retention of protein, fat and energy in broiler chickens. British Poultry Science, v.35, p.603-614, 1994.

DEATON, J.W.; LOTT, B.D. Age and dietary energy effect on broiler abdominal fat deposition. Poultry Science, v.64, p.2161-2164, 1985.

FREITAS, E.R.; SAKOMURA, N.K.; EZEQUIEL, J.M.B. et al. Energia metabolizável de alimentos na formulação de ração para frangos de corte. Pesquisa Agropecuária Brasileira, v.41, n.1, p.107-115, 2006.

GRIFFITHS, L.; LEESON, S.; SUMMERS, J.D. Fat deposition in broilers: effect of dietary energy to protein balance, and early life caloric restriction on productive performance and abdominal fat pad size. Poultry Science, v.56, p.638-646, 1977.

KESSLER, A.M.; SNIZEK JR., P.N.; BRUGALLI, I. Manipulação da quantidade de gordura na carcaça de frangos. In: SIMPOSIO INTERNACIONAL SOBRE DESENVOLVIMENTO DE CARCAÇA DE FRANGOS: OSSO, MÚSCULO, GORDURA E PENA, CONFERÊNCIA APINCO DE CIÊNCIA E TECNOlOgia AVÍCOlAS, 2000, Campinas. Anais... Campinas: APINCO, 2000. p.107-133.

LEESON, S.; CASTON, L.; SUMMERS, J.D. Broiler response to energy diet. Poultry Science, v.75, p.529-535, 1996.

MACLEOD, M.G. Energy and nitrogen intake, expenditure and retention at $20^{\circ} \mathrm{C}$ in growing fowl given diets with range of energy and protein contents. British Journal of Nutrition, v.64, p.625-637, 1990.

MORRIS, T.R.; GOUS, R.M.; FISHER, C. An analysis of the hypothesis that amino acid requirements for chicks should be stated as a proportion of dietry protein. World's Poultry Science Journal, v.55, p.7-22, 1999.

NATIONAL RESEARCH COUNCIL - NRC. Nutrient requirement of poultry. 9.ed. Washington, D.C.: National Academy of Science, 1994. 154p.
NOBRE, R.T.R.; SILVA, D.J.; TAFURI, M.L. et al. Efeito do nível de energia sobre o desempenho de diferentes grupos genéticos de frangos de corte. Revista da Sociedade Brasileira de Zootecnia, v.23, n.4, p.595-602, 1994.

NOY, Y.; SKLAN, D. Nutrient use in chicks during the first week posthatch. Poultry Science, v.81, p.391-399, 2002.

OLIVEIRA NETO, A.R.; OLIVEIRA, R.F.M.; DONZELE, J.L. et al. Níveis de energia metabolizável para frangos de corte no período de 22 a 42 dias de idade mantidos em condições de estresse de calor. Revista Brasileira de Zootecnia, v.28, n.5, p.1054-1062, 1999.

OLIVEIRA NETO, A.R.; OLIVEIRA, R.F.M.; DONZELE, J.L. et al. Níveis de energia metabolizável para frangos de corte no período de 22 a 42 dias de idade mantidos em ambiente de termoneutro. Revista Brasileira de Zootecnia, v.29, n.4, p.1132-1140, 2000.

REGINATTO, M.F.; RIBEIRO, A.M.L.; PENZ JR., A.M. et al. Efeito da energia, relação energia:proteína e fase de crescimento sobre o desempenho e composição de carcaça de frango de corte. Revista Brasileira de Ciência Avícola, v.2, n.3, p.229-237, 2000.

ROSTAGNO, H.S.; ALBINO, L.F.T.; DONZELE, J.L. et al. Tabelas brasileiras para aves e suínos (composição de alimentos e exigências nutricionais). Viçosa, MG: Editora UFV, 2000. 141p.

SILVA, D.J.; QUEIROZ, A.C. Análise de alimentos: métodos químicos e biológicos. Viçosa, MG: Editora UFV, 2002. 235p.

SILVA, J.H.V.; ALBINO, L.F.T.; NASCIMENTO, A.H. Níveis de energia e relações energia:proteína para frangos de corte de 22 a 42 dias de idade. Revista Brasileira de Zootecnia, v.30, n.6, p.1791-1800, 2001

STRINGHINI, J.H.; JARDIM FILHO, R.M.; CAFÉ, M.B. et al Programas alimentares para frangos de corte. 1. Machos. In: REUNIÃO ANUAL DA SOCIEDADE BRASILEIRA DE ZOOTECNIA, 37., 2000, Viçosa, MG. Anais... Viçosa, MG: Sociedade Brasileira de Zootecnia, 2000. (CD-ROM).

TRINDADE, D.S.; CAVALHEIRO, A.C.L.; OLIVEIRA, M.F.G. et al. Efeito do nível de energia e de proteína da dieta e do programa alimentar sobre o desempenho e composição química da carcaça de frangos para abate. Anuário Técnico do IPZFO, v.9, p.2137, 1982

WALDROUP, P.W. Nutrient requirement of broilers. In: SIMPÓSIO INTERNACIONAL SOBRE EXIGÊNCIAS NUTRICIONAIS DE AVES E SUÍNOS, 1996, Viçosa, MG. Anais... Viçosa, MG: Universidade Federal de Viçosa, 1996. p.55-63.

WALDROUP, P.W.; MITCHELL, R.J.; PAYNE, J.R. et al. Characterization of the response of broiler chickens to diets varying in nutrient density content. Poultry Science, v.55, p.130-145, 1976.

ZANUSSO, J.T.; OLIVEIRA, R.F.M.; DONZELE, J.L. et al. Níveis de energia metabolizável para pintos de corte mantidos em ambiente de conforto térmico. Revista Brasileira de Zootecnia, v.28, n.5, p.1068-1074, 1999. 